\title{
Algumas considerações sobre as abordagens construtivistas para a utilização de tecnologias na educação
}

\author{
Renato Rocha Souza*
}

Resumo Discutem-se neste artigo algumas das possibilidades de inserção e utilização de tecnologias da informação em dinâmicas pedagógicas de cunho construtivista, abordando aspectos da história recente do processo de informatização de escolas de ensino médio e fundamental, e comentando as dificuldades inerentes ao processo.

Palavras-chave tecnologia na educação, escolas de $1^{\circ}$. e $2^{\circ}$. grau, construtivismo.

\begin{abstract}
In this article are discussed some of the possibilities of adopting information technologies for pedagogical purposes in a constructivist perspective. It covers the process of introducing IT on schools in the last few decades, and analyzes the major drawbacks faced in the process.
\end{abstract}

Keywords education technology, elementary and high-schools, constructivism in education.

\section{Introdução}

Um dos campos mais férteis para o uso da tecnologia é o da educação. Podemos imaginar uma miríade de situações, desde o ensino da física através da realidade virtual a projetos de colaboração, onde podemos aplicar as tecnologias existentes para criar situações de aprendizagem. Embora existam vários livros e publicações versando sobre formas significativas de utilização da tecnologia na educação, temos percebido um grande atraso na implantação e apropriação destas metodologias e ferramentas pelas escolas e universidades. Isto ocorre em parte pelo tempo necessário para a introjeção das reflexões e atitudes fundamentais à efetivação das mudanças desejadas, e já sinalizadas em alguns centros de excelência, mas também tem a sua causa nas controvérsias conceituais, ou mesmo falta de consciência, sobre o que se pretende com a adoção de recursos tecnológicos no processo educacional.

Não faz parte desta análise a abordagem das questões sociais e políticas que determinam a exclusão de muitos espaços educacionais, notadamente os da rede pública de ensino, da "comunidade tecnológica" - muitos trabalhos já foram apresentados neste sentido. Os problemas de acesso deficitário, porém, devem ser atacados em paralelo às reflexões sobre as melhores formas de apropriação tecnológica, porque a ignorância de qualquer destes aspectos pode gerar atrasos onerosos no desenvolvimento da sociedade.

\footnotetext{
* Renato Rocha Souza é Doutor em Ciência da Informação - UFMG e Professor adjunto da Escola de Ciência da Informação - UFMG
} 
Considerando o fracasso da introdução de tecnologias da informação nas redes públicas, e abordando especificamente a experiência das instituições particulares de ensino médio e fundamental em países da América Latina, e mesmo em outros países que adotaram nas duas últimas décadas o modelo de laboratórios de informática, estamos assistindo, com honrosas exceções, a poucas experiências propaladamente bem sucedidas; mais freqüentemente observamos processos constantes de reflexão e revisão de rumos, quando não de incorporação silenciosa das atividades de introdução de tecnologia informática no rol das disciplinas de cunho conteudista, empregando e perpetuando assim os métodos tradicionais de ensino e avaliação.

$\mathrm{Na}$ maioria destas escolas, a utilização da informática tem acontecido de forma desconexa e compartimentada pelas disciplinas temáticas. É utilizado predominantemente software de apoio à instrução para o ensino de determinados conteúdos. Além disso, e apesar de todas as discussões e experiências positivamente destoantes, o ensino não é contextualizado no meio social do aluno assim como não são aproveitados os seus conhecimentos prévios. Os programas de computador não permitem a colaboração de alunos e professores e, antes, chegam mesmo a propor a substituição da figura do professor ou o "reforço" do aprendizado de certos conteúdos.

Não se pretende neste artigo a realização de uma análise dos motivos - formação deficiente dos professores, falta de interesse ou ousadia das instituições para a inovação, falta de recursos, apego ao status quo, limitação no modelo de seleção para as universidades (o vestibular), que incentiva o ensino conteudista, etc. - que levam a estes problemas. Estas questões são complexas

e imbricadas demais para uma análise ligeira. Antes, pretende-se abordar como as diferentes visões de processos de ensino e aprendizagem se coadunam com as ferramentas tecnológicas disponíveis na estruturação e planejamento do ambiente escolar. Para isso, organizamos a reflexão através de algumas questões norteadoras, cujas respostas devem orientar o processo por vezes irrefletido - de adoção de tecnologias na escola. A primeira destas perguntas é:

\section{Qual a concepção do processo de ensino e aprendizagem?}

Muitas vezes adotam-se recursos tecnológicos com a visão de que por si só serão capazes de intervir e auxiliar os processos educacionais, mas a forma como entendemos estes processos e as visões pedagógicas subjacentes são as primeiras grandes influências que se fazem sentir. Segundo Moreira, Costa e Oliveira (2001), são três as principais concepções de aprendizagem que norteiam a prática pedagógica da tecnologia educacional, apresentadas a seguir:

\section{Concepção empirista}

Segundo esta corrente, o processo ensino-aprendizagem caracteriza-se pela ação determinante dos estímulos selecionados pelo professor, que escolhe conteúdos didáticos e instrumentos com vista à aquisição de conhecimentos pelo aluno. O aluno é passivo e considerado como uma tabula rasa - ou "disquete virgem", para usar uma metáfora moderna - onde serão depositados os conteúdos. Paulo Freire (1970) chamou a este processo de "educação bancária", pois estava baseado em "depósitos" de conhecimento que eram realizados no "banco" do aluno. O conhecimento, nesta concepção, é atomístico e não relacional. 
O uso de tecnologias segundo esta visão será baseado apenas num "transplante" de conteúdos de instrução programada para o ambiente tecnológico, com a justificativa de permitir a adequação aos ritmos individuais de absorção de conhecimento. As ferramentas utilizadas serão aquelas que utilizam os recursos de multimídia - textos, sons, animações e vídeos - para oferecer o acesso aos conteúdos de forma mais agradável, com momentos avaliativos em que são testados os conhecimentos adquiridos. Tomada isoladamente, esta talvez seja a estratégia mais pobre de utilização de tecnologias no ensino, pois não há grandes mudanças paradigmáticas e pouco aproveitamento em termos de educação para o desenvolvimento humano. Por outro lado, a disponibilização de materiais bibliográficos de consulta através de novos suportes nos vários meios pode estimular e facilitar a busca autônoma pelo conhecimento, razão pela qual as enciclopédias e recursos informáticos nos meios digitais têm o seu lugar assegurado, como recursos didáticos auxiliares.

\section{Concepção racionalista}

Segundo a concepção racionalista, o processo de aprendizagem é regulado pelo amadurecimento orgânico das estruturas racionais, pré-formadas no aluno. Este amadurecimento paulatino é que confere significado aos objetos de aprendizagem, num processo autônomo que não necessita de mediação, contrapondo-se às teorias empiristas baseadas em estímulos e aferição das respostas. Os pesquisadores das escolas da Gestalt acreditavam que o processo de amadurecimento das estruturas concede ao aluno sucessivos insights que lhe permitirão entender os processos e fenômenos no meio social.

Segundo esta visão, o uso de ferramentas tecnológicas é absolutamente acessório, sendo apenas consideradas para a mensuração dos estágios de desenvolvimento cognitivo - como nos testes de QI - ou mesmo em jogos ou atividades em que são desveladas fases, a serem investigadas seqüencialmente, na medida em que se alcança um completo entendimento dos estágios anteriores. As atividades de conhecimento são centradas no aluno, que depende exclusivamente do seu potencial cognitivo para alcançar a aprendizagem (MOREIRA; COSTA; OLIVEIRA, 2001).

\section{Concepção construtivista}

A concepção construtivista do processo de ensino e aprendizagem foi fortemente influenciada pelas teorias sociointeracionistas, que procuravam superar as dicotomias estabelecidas pelo antagonismo entre as linhas empirista e racionalista. $O$ enfoque construtivista enfatiza a construção de novo conhecimento e maneiras de pensar mediante a exploração e a manipulação ativa de objetos e idéias, tanto abstratas como concretas, e explicam a aprendizagem através das trocas que o indivíduo realiza com o meio. Os trabalhos de maior influência para a concepção construtivista foram os de Piaget (1896-1980) e Vygotsky (1896-1934), e esta tem sido apropriada por diversos autores que expandiram seu escopo e desenvolveram novas abordagens. A abordagem construtivista é a que tem gerado mais benefícios e a que melhor contextualiza e aproveita os recursos tecnológicos para os processos de ensino e aprendizagem. 
A concepção construtivista forneceu a base epistemológica para algumas teorias posteriores, como a de aprendizagem colaborativa e a de aprendizado significativo, apresentadas a seguir.

\section{Aprendizagem colaborativa e significativa}

A aprendizagem colaborativa (AUSUBEL; NOVAK; HANESIAN, 1978) é uma atividade na qual os estudantes e possivelmente os seus professores constroem cooperativamente um modelo explícito de conhecimento. De um ponto de vista construtivista, o resultado mais importante do processo de modelagem não é o modelo em si, mas principalmente a apreciação e a experiência que se obtêm ao perseguir a articulação, organização e avaliação críticas do modelo durante o seu desenvolvimento (CAÑAS; FORD, 1992; CAÑAS, 1998). Para isso, um processo colaborativo deve oferecer atividades nas quais os estudantes possam expor qualquer parte do seu modelo - incluindo as suas suposições e seus conhecimentos prévios - a um escrutínio crítico por parte dos outros estudantes. Desta forma, as ferramentas desenvolvidas para dar suporte a estes ambientes devem poder ajudar alunos e professores a expressar, elaborar, compartilhar, melhorar e entender as suas criações.

A teoria de aprendizado significativo (AUSUBEL; NOVAK; HANESIAN, 1978) - que tem exercido uma enorme influência na educação - baseia-se num modelo construtivista dos processos cognitivos humanos. Em particular, a teoria da assimilação descreve como o estudante adquire conceitos, e como organiza-se a sua estrutura cognitiva. Segundo este autor, "o aprendizado significativo acontece quando uma informação nova é adquirida mediante um esforço deliberado por parte do aprendiz em ligar a informação nova com conceitos ou proposições relevantes preexistentes na sua estrutura cognitiva". (AUSUBEL; NOVAK; HANESIAN, 1978, p. 159). Isto vai ao encontro da teoria psicogenética de Piaget $(1971 ; 1972)$ de adaptação através da assimilação e acomodação de conhecimentos. As etapas da teoria de assimilação acentuam que o aprendizado significativo requer que a estrutura cognitiva do aprendiz contenha conceitos base com os quais idéias novas possam ser relacionadas. Por isto, Ausubel argumenta que o fator individual mais importante que influi na aprendizagem é aquilo que o estudante já sabe. Deve-se primeiro determinar quanto sabe, e depois ensinar-lhe de acordo com este conhecimento prévio. A aprendizagem significativa envolve a assimilação de conceitos e proposições novas mediante a sua inclusão nas estruturas cognitivas e referenciais simbólicos existentes. Os resultados cheios de significado surgem quando uma pessoa, consciente e explicitamente, estabelece ligações deste novo conhecimento com os conceitos relevantes que ela já possui.

Estas teorias e perspectivas apresentam-se extremamente desejáveis e adequadas para embasar uma experiência bem sucedida de informática educativa. No entanto, os ambientes de educação tradicionais usualmente não estão organizados para este tipo de atividades de ensino, e as tecnologias da informação disponíveis para apoiar a educação não ajudam o professor a criar este ambiente construtivista de aprendizagem significativa, e muito menos de aprendizagem colaborativa. Este fato leva-nos à segunda questão norteadora, sobre as tecnologias a serem utilizadas dentro do rol disponível de tipos de recursos tecnológicos e a forma de sua utilização.

\section{Quais as tecnologias que vale a pena adotar, e como poderiam ser utilizadas?}


Se partirmos de uma abordagem construtivista, podemo-nos perguntar: este aprendizado auxiliado pela tecnologia é significativo, do ponto de vista da formação do aluno? Os recursos tornados disponíveis contribuirão para um ganho significativo na formação do indivíduo? $\mathrm{Ou}$ estaremos constantemente introduzindo novidades tecnológicas que, quando perdem o apelo "pirotécnico" inicial, ou quando deixam de oferecer um diferencial de marketing para o estabelecimento, são relegadas ao ostracismo?

O uso de uma tecnologia, por si só, não garante melhora à educação. Num exemplo tolo, poderíamos tomar uma invenção simples como o lápis: ele poderia ser usado para escrever um artigo memorável, para fazer uma batucada na carteira ou para furar os olhos de outra pessoa. Assim acontece com a tecnologia. Dependendo da forma como é utilizada, pode revolucionar ou perpetuar as estruturas de ensino existentes. Acontece que a idéia tradicional de escola está tão profundamente enraizada na imagética, e refletida nas atitudes dos atores, que quando são propostas algumas formas de adoção de tecnologia, tende-se a imaginar como esta pode auxiliar na melhora dos métodos conhecidos de ensino e aprendizagem - e raramente são repensados os processos fundamentais que operam no ambiente escolar. A preocupação dos gestores raramente passa pela utilização das tecnologias como forma de propiciar um projeto educacional que reflita a nossa concepção de ensino e aprendizagem.

Tendo isto posto, vamos apresentar um panorama de algumas das ferramentas disponíveis, discutindo em cada caso algumas possíveis formas de apropriação para contribuir para o ensino numa perspectiva construtivista. As ferramentas apresentadas são resultados da convergência de tecnologias e metodologias recentes, como software hipermídia de autoria, os recursos da web e da internet, a inteligência artificial, mapas conceituais; com a perspectiva de aprendizagem construtivista, colaborativa e significativa. As ferramentas propostas como eixo destas experiências permitem a construção do conhecimento por parte do aprendiz e são consideradas "abertas", na medida em que não trazem informações prévias em excesso aos alunos - apenas um pequeno conjunto de regras para a sua utilização. Desta forma, professores e alunos estão livres para trabalhar os conteúdos relevantes ao processo de ensino e aprendizagem em questão. Além disso, demandam um constante intercâmbio e reformulação de idéias, num processo cognitivo de interação e social, que propicia a criação de um ambiente de aprendizado significativo. Estas características são extremamente desejáveis na educação.

Dentro das ferramentas, são apresentadas a linguagem Logo, os sistemas de autoria e multimídia, a internet com os seus espaços e possibilidades, como os webquests; os ambientes de simulação e realidade virtual, entre outros.

\section{A linguagem LOGO}

A linguagem LOGO foi desenvolvida em 1967 no Laboratório de Inteligência Artificial do MIT (Massachusetts Institute of Technology), pela equipe chefiada por Seymour Papert, tendo como base a teoria de Piaget e algumas idéias da Inteligência Artificial (PAPERT, 1977, 1980, 1993). Embora tenha sido projetada para o uso na educação, é interessante notar que deriva da linguagem LISP, que é utilizada para o desenvolvimento de sistemas de inteligência artificial

Como afirma Papert, a linguagem Logo representa uma modalidade de uso de computadores como instrumentos para a exploração de idéias. O seu uso freqüente pode colocar em evidência o 
processo intelectual realizado por quem o utiliza, evidenciando os seus erros e facilitando a correção de falhas de raciocínio lógico.

Com a disseminação dos microcomputadores, o Logo passou a ser adotado e usado em muitas escolas. Esse mesmo interesse já não existe hoje, e esse desencanto com o Logo aconteceu, em grande parte, porque a apropriação do Logo pelas instituições de ensino não foi muito cuidadosa. Os escritos de Papert e os relatos das experiências usando Logo sugeriram que a ferramenta era intuitiva e abrangente o suficiente para ser usada em qualquer espaço, com quaisquer faixas etárias. Sem, porém, a preparação adequada do professor, os resultados obtidos foram muito aquém do que havia sido esperado. O Logo ficou conhecido pelo fato de ter prometido muito e fornecido muito pouco como retorno, e hoje sabemos que o papel do professor no ambiente Logo é fundamental. Mas a ferramenta, a despeito do constante aparecimento de tecnologias educacionais no mercado, ainda não encontrou concorrente à altura, em termos de possibilidades de desenvolvimento de experiências lógico-matemáticas para o aluno ao mesmo tempo em que fornece um ambiente para construção do conhecimento. Entre as versões mais conhecidas, temos o LCSI Micromundos (www.microworld.com) e o Superlogo (www.logo.com), entre muitas outras, e algumas até mesmo gratuitas.

\section{Sistemas de Autoria Multimídia e Hipermídia}

Embora os termos Multimídia e Hipermídia sejam constantemente usados indiscriminadamente, existe uma diferença entre os dois. Multimídia refere-se à integração de dois ou mais meios de informação (mídias) num sistema de computador. Estes meios podem incluir textos, imagens, áudio, vídeo e animações, e com os baixos preços dos dispositivos de Realidade Virtual, podemos esperar que se integrem mais amplamente dispositivos de feedback táctil, olfativo, visual, etc. Hipermídia é a extensão do paradigma do hipertexto, com a inclusão de outros meios. Fazer a distinção é importante, pois nem todo sistema multimídia é hipermídia, embora um sistema hipermídia sempre utilize recursos de multimídia, numa disposição de navegação possivelmente não linear, através de conceitos, associações e nós (RILEY, 1994).

O grande apelo pedagógico da multimídia é o fato de estar baseada nas habilidades naturais humanas de processamento de informações. Os nossos olhos e ouvidos, em conjunto com o nosso cérebro, compõem um formidável sistema para transformar dados sem sentido em informação, embutindo estes dados de significado. Para o estudante, uma das primeiras vantagens de software multimídia é o fato de serem programas mais agradáveis de se utilizar, além da possibilidade de interação do usuário com a aplicação, na medida em que este escolhe os caminhos a serem seguidos na sua navegação, utilizando o potencial pleno de fala, audição, controles manuais e por vezes feedback táctil.

Se adicionarmos a estas vantagens o fato de, quando utilizando sistemas de autoria em multimídia, os alunos poderem construir os seus ambientes de interação, podemos notar a capacidade destas aplicações de prover ambientes de aprendizado "construcionistas" sendo que o construcionismo é a utilização de uma ferramenta aberta com a filosofia pedagógica construtivista (PAPERT, 1977). Existem muitos pacotes que permitem a implantação de ambientes de autoria, sendo os mais simples aqueles baseados nas tecnologias web.

Assim como a linguagem Logo, também foram dissecadas experiências bem sucedidas de utilização de sistemas de autoria e multimídia para organização e exteriorização das idéias 
construídas, de forma audiovisual, em ambientes educacionais. Muitas implementações de ambientes são ao mesmo tempo simples e poderosas, e extremamente versáteis para a construção de projetos e integração de conteúdos. Infelizmente, na grande maioria dos projetos de informatização são pobremente exploradas as suas enormes possibilidades de utilização para a educação.

\section{Ambientes baseados na internet}

A internet - e sua quintessência, a web - seriam merecedoras de um capítulo à parte. É frequientemente apontada como a melhor ocorrência dos últimos anos para a educação por diversas fontes. Como comenta Rudenstine (1997), a internet:

- pode prover acesso a fontes ilimitadas de informações, não convenientemente obteníveis através de outras maneiras;

- permite a criação de materiais de cursos extremamente ricos;

- amplia o processo vital de aprendizado "dialético";

- cria uma gama de novos fóruns eletrônicos para tais aprendizados;

- reforça a concepção de aprendizes como agentes ativos no processo de aprendizagem, e não receptores passivos de conhecimento por parte de professores ou livros-textos.

E estas são apenas algumas das possibilidades. Hoje, mais de uma década após o lançamento deste texto de Rudenstine, as opções são incrivelmente maiores. No entanto, tem sido um desafio para as escolas capitalizar todo esse potencial para a criação de ambientes ricos em aprendizagem. Talvez aconteça em parte pelas barreiras estruturais do ambiente escolar. As mudanças, porém, por que têm passado a sociedade mundial e o fenômeno de surgimento da "sociedade em rede" apontada por Castells (1996) podem precipitar a revisão e queda destas barreiras, o que abriria espaço para a otimização do seu uso. Existem algumas correntes que consideram que o excesso de informações disponíveis mais atrapalha do que ajuda como Talbot, que diz: "se a educação apresenta problemas, nunca foi por que faltavam meios e fontes de informação" (TALBOT, 1997). Estas correntes, entretanto, ignoram o potencial da internet para a educação, não somente por disponibilizar informação, mas pelas formas facilmente recuperáveis que disponibiliza, e por permitir a interação, autoria e disseminação destas informações num âmbito mundial.

A utilização destes ambientes baseados na internet para fins educacionais é limitada apenas pela criatividade, e as possibilidades são diversas. Cabe ao gestor educacional combinar a filosofia construtivista com as tecnologias para gerar ambientes de aprendizagem significativa e, possivelmente, colaborativa, contextualizando atividades desafiadoras de desenvolvimento de competências e habilidades específicas previamente selecionadas com as tecnologias que as propiciam. Ultimamente, temos assistido ao surgimento de dezenas de novas tecnologias baseadas na Internet e na web para a criação de ambientes de colaboração e aprendizagem. Entre os vários ambientes existentes, com vocação para utilização em projetos de ensino e aprendizagem, podemos destacar os seguintes: 


\section{E-mail e listas de discussão}

O e-mail é também o componente básico que constitui suporte para a interação entre grupos de pessoas de todo o mundo, através das redes de comunicação, como a Internet. A sua utilização, que independente do local, tempo ou combinação prévia entre remetente e destinatário, o torna extremamente versátil, aliado ao fato de que, na maioria das implementações de software para correio eletrônico, podem ser anexados nas mensagens quaisquer tipos de documentos e formatos de dados produzidos por computador. Uma mensagem de e-mail pode ser enviada para um ou para um número finito de destinatários fixos, como no caso das listas de discussão.

A abundante disponibilidade dos serviços gratuitos de webmail ${ }^{1}$ adicionou facilidade de acesso às mensagens individuais; a partir de qualquer lugar onde esteja o usuário, desde que possua um navegador e ligação à Internet, poderá enviar e receber as suas mensagens. Ao permitir a comunicação de grupos de alunos, o e-mail torna-se um componente básico de qualquer projeto colaborativo via Internet, onde estes grupos intercambiam informações regularmente para compartilhar tarefas, informações e atividades. O e-mail é usado em conjunto com a maioria dos outros recursos da Internet, na estruturação de projetos educacionais.

\section{Ambientes de conversação on-line, ou chats}

O nome dos ambientes de conversação on-line deriva do verbo de língua inglesa to chat, que significa "conversar de forma informal ou familiar". Para conversar com pessoas num chat, todos os interlocutores devem estar conectados à Internet ao mesmo tempo.

Os chats podem ser baseados em texto, com a interface de linha de caracteres, ou podem utilizar interfaces gráficas, possibilitando as formas mais variadas de expressão de idéias e sentimentos. Possibilitam a interação em tempo real através da troca de frases, expressões ou até gestos, dependendo dos recursos disponíveis em cada implementação. Os chats são ideais para a discussão de assuntos nos quais a interação síncrona é fundamental, e por este caráter de interação em tempo real, a adequação e o planejamento prévio entre os participantes do momento de utilização é imprescindível.

Com a melhoria das velocidades médias de comunicação e decréscimo de custos de acesso, tornaram-se comuns as modalidades de chat com vídeo, onde os participantes interagem visualmente, através de webcams instaladas nos seus computadores.

Muitas vezes, o encontro de alunos que estejam separados fisicamente e que planeiam estabelecer trabalhos em conjunto num ambiente de chat público é favorável, para estabelecer as bases da cooperação. Também é comum acontecerem chats agendados por um moderador, com personalidades ou pessoas influentes e populares nos assuntos em questão. Estas sessões de entrevistas coletivas em chats são transcritas em arquivos texto, para posterior consulta.

\footnotetext{
${ }^{1}$ Sites na Internet, quase sempre financiados por anunciantes, que disponibilizam uma conta gratuita de correio eletrônico para os usuários que se registram.
} 


\section{Ambientes de imersão virtual}

Os ambientes de imersão são espaços de interação virtualmente suportados, ou seja, criados através de um servidor que executa um programa específico e dá suporte às conexões e ações dos usuários. A interação dá-se através de representações gráficas, habitualmente chamadas de avatares, ou através de frases em linhas de caracteres, como nos chats. Nos primórdios da Internet já encontrávamos ambientes de imersão baseados em texto, como os primeiros MUDs e MOOs $^{2}$, que rapidamente evoluíram no sentido de apresentar interfaces gráficas e ampla gama de escolha de avatares. Estes ambientes foram originalmente projetados para suportar os role playing games ${ }^{3}$ on-line, mas têm desde então evoluído bastante, no sentido de proporcionarem ambientes propícios à manutenção de comunidades profissionais ou de interesse.

A diferença entre os ambientes de imersão e os chats é que, nestes últimos, o contexto é criado no momento da conversação; basicamente, o contexto é a conversação. Nos ambientes de imersão, há toda uma construção abstrata do espaço virtual, que pode ter sido feita previamente ou no momento da interação, pelos criadores do ambiente, ou mesmo pelos usuários.

A realidade virtual, ou simplesmente $\mathrm{RV}$, é a simulação de um ambiente real ou imaginário, que pode ser experimentado visualmente em três dimensões e até mesmo oferecer feedback táctil, sonoro e olfativo, aproximando-se cada vez mais da experiência da realidade concreta. $\mathrm{O}$ desenvolvimento de interfaces de realidade virtual para a criação de ambientes de imersão é um dos campos ainda muito pesquisados na atualidade, e para o qual convergem estudos em informática, psicologia, robótica, ergonomia cognitiva e inteligência artificial.

Os grandes empecilhos para a popularização dos ambientes mais elaborados de imersão virtual com interação de pares ainda são os custos dos equipamentos e a baixa velocidade de transmissão de dados, necessária para transmitir informações em tempo real. Mas estes custos tendem a diminuir, na medida em que os dispositivos forem fabricados em maior escala, e na medida em que o acesso em banda larga estiver mais disseminado.

A RV, infelizmente, é ainda subutilizada em espaços educacionais pelos motivos expostos acima. Mas já há muitas empresas que oferecem pacotes para serem utilizados em sala de aula a baixo custo.

\section{Programas de suporte a comunidades virtuais}

Uma comunidade virtual pode ser definida como uma comunidade de pessoas compartilhando interesses comuns, idéias e relacionamentos, através da internet, ou outras redes colaboradoras. As comunidades virtuais começaram a surgir com as listas de discussão e a usenet, mas ganharam mais recursos com os programas sinalizadores de presença, também chamados de

\footnotetext{
${ }^{2}$ Multi User Dungeons/Domains, e MUDs Object Oriented, respectivamente.

${ }^{3}$ Os role playing games são jogos nos quais cada participante assume o papel de um personagem, que interage com o ambiente de fantasia do jogo e com os outros personagens, seguindo as características físicas e psicológicas que foram por eles adoptadas ou impingidas pela sorte.
} 
sistemas de messaging, disseminados após o sucesso instantâneo do $\mathrm{ICQ}^{4}$. As funções dos vários programas incluem hoje, além da possibilidade de anunciar a presença on-line para colegas e conhecidos que estejam conectados e a utilizar o programa, o chat com múltiplos parceiros, envio de e-mail, troca de arquivos, troca de páginas da web, troca de mensagens e recados em texto e voz, espaço para página web pessoal, espaço para álbuns de fotos, imagens de webcam, páginas amarelas de usuários e troca de informações sobre interesses comuns e afinidades, entre outras. Hoje existem diversas modalidades e implementações de espaços para suporte de comunidades de interesse, desde os diários pessoais interativos chamados weblogs (ou simplesmente blogs) como o Blogger (http://www.blogger.com), o Fotolog (http://www.fotolog.net), de compartilhamento de fotografias; até os espaços de networking, como o Orkut (http://www.orkut.com); ou os controversos programas de compartilhamento de arquivos - criados a partir do famoso Napster - como o Limewire (http://www.limewire.com), entre outros. A diversidade é incrível, e por vezes torna-se difícil escolher ou mesmo imaginar a forma de utilizar espaços como estes para atividades formais de ensino e aprendizagem. Há uma miríade de possibilidades, e recomenda-se planejar antecipadamente as atividades e conhecer bem as ferramentas que se deseja utilizar, aproveitando o melhor de cada uma, e ainda assim mantendo o foco nos objetivos almejados.

\section{Webquests}

As webquests são um modelo extremamente simples e rico para dimensionar usos educacionais da $w e b$, com fundamento na aprendizagem cooperativa e processos investigadores na construção do saber. A metodologia foi proposta por Bernie Dodge em 1995 e hoje já conta com mais de dez mil páginas na web, com propostas de educadores de diversas partes do mundo. A dinâmica da webquest procura evitar que o uso da web seja um dispersivo e inútil registro de dados sem relevância que não agregam qualidade pedagógica; pelo contrário, procuram propiciar um processo de busca de informações valioso na construção do conhecimento, gerando um rico ambiente interativo, facilitador e motivador de aprendizagem. As webquests têm se mostrado uma metodologia eficaz para motivar alunos e professores no uso da Internet voltado para o processo educacional, estimulando a pesquisa, o pensamento crítico, o desenvolvimento de professores, a produção de materiais e o pensamento crítico e protagonismo juvenis.

Em linhas gerais, uma webquest parte da definição de um tema e objetivos por parte do professor, uma pesquisa inicial e disponibilização de links selecionados acerca do assunto, para consulta orientada dos alunos. Estes devem ter uma tarefa, exeqüível e interessante, que norteie a pesquisa. Para o trabalho em grupos, os alunos podem assumir papéis diferentes, como o de especialistas, visando gerar trocas entre eles. Tanto o material inicial como os resultados devem ser publicados na web, on-line.

As webquests não exigem software específico além dos programas utilizados habitualmente para navegar na rede, produzir páginas, textos e imagens. Isso faz com que seja muito fácil usar a capacidade instalada em cada escola, sem restrição de plataforma ou soluções, centrando a produção de webquests na metodologia pedagógica e na formação de docentes. Há boas

\footnotetext{
${ }^{4}$ ICQ é um software pioneiro de messaging, cujo nome é um trocadilho com a pronúncia das letras em inglês, que se parece com a frase 'I seek you' ou 'Eu procuro-o'. Para um melhor entendimento do seu funcionamento, visite o site www.icq.com.
} 
informações sobre as webquests nos endereços http://webquest.sdsu.edu e http://www.webquest.futuro.usp.br.

\section{Mapas conceituais}

Os mapas conceituais, desenvolvidos por Joseph Novak (1977), são utilizados como uma linguagem para descrição e comunicação de conceitos. Representam uma estrutura que vai desde os conceitos mais abrangentes até aos menos inclusivos. São utilizados para auxiliar a ordenação e a seqüência hierarquizada dos conteúdos de ensino, de forma a oferecer estímulos adequados ao aluno. Em ambientes educativos, os mapas conceituais têm ajudado pessoas de todas as idades a examinar os mais variados campos de conhecimento (NOVAK; GOWIN, 1984). Na sua essência, provêem representações gráficas de conceitos, num domínio específico de conhecimento, construídas de tal forma que as interações entre os conceitos são evidentes. Os conceitos são conectados por arcos, formando proposições mediante frases simplificadas.

Como uma ferramenta de aprendizagem, o mapa conceitual é extremamente útil para o estudante, por exemplo, para fazer anotações, resolver problemas, planejar o estudo, preparar esquemas conceituais, preparar-se para avaliações e identificar a integração dos tópicos. Para os professores, os mapas conceituais podem constituir-se em poderosos auxiliares nas suas tarefas rotineiras, tais como ensinar novos tópicos, reforçar a compreensão, identificar conceitos mal compreendidos e avaliar de uma forma aberta os conhecimentos do aluno. Em organizações, os mapas conceituais têm sido utilizados para registrar conhecimento especialista, capturar e disseminar conhecimento tácito e para a comunicação de idéias de uma forma que se aproxima da cognição humana.

Algumas ferramentas de mapas conceituais permitem a construção colaborativa de mapas e a publicação destes na internet. Uma poderosa (e gratuita) implementação do conceito pode ser conseguida em http://cmap.ihmc.us.

\section{Discussão: o papel do professor}

A despeito das possibilidades tecnológicas acima apresentadas, entendemos que o papel do educador é possibilitar que todos aqueles recursos, dinâmicas, tecnologias e metodologias, que normalmente se abrigam sob a égide da informática, possam auxiliar os processos de ensino e aprendizagem, através da criação de situações de âmbito construtivista. Nesta visão, pode-se planejar não somente a aprendizagem de conteúdos - trabalhados através de projetos interdisciplinares com temas transversais - e o desenvolvimento de competências e habilidades desejáveis, mas também o trabalho com temáticas diversas daquelas propostas e contidas nos escopos das disciplinas tradicionais, em dinâmicas independentes. No esteio deste processo, observa-se a apropriação dos espaços tecnológicos por parte dos alunos e professores, contribuindo para aumentar a inserção destes no nosso panorama sócio-técnico.

Acredito, porém, que será necessária uma nova geração de docentes e gestores de tecnologia, educados em ambientes sensíveis a estas necessidades, para implementar de forma mais generalizada estas idéias. E mais do que isto: as idéias precisam ser compartilhadas por 
administradores escolares, coordenadores de ensino e pais de alunos, por vezes os mais avessos a mudanças e experimentalismos.

São muitos os atores responsáveis pelo sucesso das iniciativas. O papel da equipe responsável pela implantação de recursos tecnológicos para objetivos educacionais assemelha-se ao de facilitadores do acesso e mediadores de dinâmicas. Sua responsabilidade é conjunta com a dos professores, de procurar as melhores formas de utilização das ferramentas tecnológicas dentro do contexto das suas escolas, exercitando o bom senso, a sensibilidade pedagógica e construindo a todo instante uma perspectiva que seja ao mesmo tempo integradora e revolucionária, porque somente as mudanças paulatinas podem ser bem sucedidas na tradicional estrutura escolar. Os gestores, por sua vez, são fundamentais quando estão atentos à possível apatia causada pela dificuldade de avaliação do sucesso do trabalho no curto prazo. Daí, exercitando a criatividade, a autonomia, a pró-atividade e o sentido crítico podem ampliar e atribuir novo significado ao que é sugerido como linha de ação da organização escolar.

Entendemos que para atingir este objetivo, algumas ações de base contínua são extremamente desejáveis, como:

- apresentar e facilitar o acesso dos professores e alunos aos recursos e tecnologias disponíveis;

- coadunar as competências e habilidades que se desejam desenvolver no aluno através de dinâmicas compatíveis com as ferramentas apropriadas;

- transformar e atribuir novo significado aos conteúdos das disciplinas tradicionais através de temáticas transversais e contextos integradores;

- interagir com professores e coordenadores procurando identificar possíveis pontos de inserção das tecnologias no espaço letivo usual das disciplinas;

- questionar continuamente a práxis, para que se possam atingir os objetivos pedagógicos, com objetivos de curto, médio e longo prazo;

- questionar a validade do uso da tecnologia na obtenção destes objetivos, à luz de propostas mais econômicas que sejam de igual forma eficazes.

Como foi dito anteriormente, existem muitas metodologias de introdução de informática no processo de ensino e aprendizagem, utilizando ferramentas abertas e dinâmica de desenvolvimento de projetos, individuais ou coletivos, de forma significativa. Cabe aos gestores e seus colaboradores iniciar um processo sustentado de apropriação de tecnologias que combata o idealismo ingênuo: as escolas são talvez das estruturas mais tradicionais na sociedade, e mais resistentes à mudança. É complexo lidar com o alto custo de adoção de tecnologias de ponta em base constante, escolhendo de forma criteriosa equipamentos e software, tendo em conta as opções mais econômicas, e aproveitando ao máximo cada recurso investido. Mas o maior ganho que pode surgir deste investimento é aproveitar o mote da tecnologia na educação para iniciar um processo maior de reflexão sobre a estrutura do processo tradicional de ensino e aprendizagem como um todo.

\section{Referências}


AUSUBEL, D. P.; NOVAK, J. D.; HANESIAN, H.; Educational psychology: a cognitive view. 2. ed. New York: Holt, Rinehart \& Winston, 1978. Reprinted. New York: Warbel \& Peck, 1986.

CAÑAS, A. J. Algunas ideas sobre la educación y las herramientas computacionales necesarias para apoyar su implementación. Pensacola, FL: Florida Institute for Human and Machine Cognition, 1998.

CAÑAS, A. J.; FORD, K. An environment for collaborative knowledge building. Toronto, 1992. Trabalho apresentado no Workshop on the Technology and Pedagogy for Collaborative Problem Solving as a Context for Learning.

CASTELLS, M. The rise of the network society. Malden, MA: Blackwell, 1996.

FREIRE, P. Pedagogia do oprimido. 3. ed. Rio de Janeiro: Paz e Terra, 1975.

MOREIRA, M., COSTA, J.W., OLIVEIRA, C.C. Ambientes informatizados de aprendizagem. São Paulo: Campinas, 2001.

NOVAK, J. D. A theory of education. Ithaca, NY: Cornell University Press, 1977.

NOVAK, J. D.; GOWIN, D. B. Learning how to learn. New York: Cambridge University Press. 1984.

PAPERT, S. A learning environment for children. In: SEIDEL, R.J.; Rubin, M.L. (Ed.) Computers and communications: implications for education. New York: Academic Press, 1977.

. Mindstorms: children, computers and powerful ideas. New York: Basic Books, 1980. Traduzido para o português em 1985, como Logo: computadores e educação. São Paulo: Brasiliense, 1980.

. The children's machine: rethinking school in the age of the computer. New York: Basic Books, 1993.

PIAGET, J. Ensaio da lógica operatória. Porto Alegre: Globo, 1971.

Gênese das estruturas lógicas elementares. Rio de Janeiro: Forense, 1972.

RILEY, Fred. Understanding IT: a review of hypermedia authoring packages. [S.1.]: University of Hull, 1994.

RUDENSTINE, Neil. The internet and education: a close fit. Disponível em: <http://www.ncac.org/cen_news/cn65internetand.html>. Acesso em: mar. 2004.

TALBOT, Stephen. Wired classroms: what you are not hearing. Disponível em: <http://www.oreilly.com/people/staff/stevet/netfuture/fwd/1997/1.html>. Acesso em: abr.1999

VIGOTSKY, L. S. Pensamento e linguagem. São Paulo: Martins Fontes, 1987. 